\title{
Intermittent Hyperinsulinaemia and Arterial Glycosaminoglycans in Dogs
}

\author{
O. V. Sirek, A. Sirek and E. Cukerman \\ Department of Physiology and Division of Teaching Laboratories, Faculty of Medicine, University of Toronto, Toronto, Ontario, Canada
}

Summary. The effect of insulin on the glycosaminoglycan content of the arterial ground substance was compared in age-matched alloxan-diabetic dogs, hypophysectomized dogs and normal controls. Hyaluronic acid and the three sulphated components, heparan, dermatan and isomeric chondroitin sulphates were quantitatively determined in the arch, thoracic and abdominal aorta, and in the carotid, coronary, iliac, renal and mesenteric arteries. Diabetic animals were either well or poorly controlled. Six well controlled dogs with a fasting mean plasma glucose level of $8.5 \mathrm{mmol} / 1$ were given around 30 units of porcine insulin/day and showed fluctuations in plasma insulin concentrations between 24 and 175 $\mathrm{mU} / \mathrm{l}$. Four poorly controlled dogs with a mean fasting plasma glucose level of $18.5 \mathrm{mmol} / \mathrm{l}$ received an average of 14 units of insulin/day, and the fluctuations ranged from 8 to $113 \mathrm{mU} / \mathrm{l}$. Eight normal, untreated controls showed mean fluctuations between 15 and $22 \mathrm{mU} / \mathrm{l}$. Within 14 weeks of insulin treatment, well controlled animals displayed glycosaminoglycan alterations in five arterial segments, usually involving more than one glycosaminoglycan constituent. In poorly controlled animals the number of segments that showed glycosaminoglycan alterations was the same, but abnormalities were limited to one of the sulphated components only. The coronary arteries displayed identical glycosaminoglycan alterations in the two groups of diabetic dogs, namely a significant rise in dermatan sulphate content $(\mathrm{p}<$ 0.01 , mean \pm SEM) from the normal value of $1.12 \pm$ $0.03 \mathrm{mg} / \mathrm{g}$ dry defatted tissue to $1.31 \pm 0.03 \mathrm{mg} / \mathrm{g}$ in well controlled animals and to $1.37 \pm 0.08 \mathrm{mg} / \mathrm{g}$ in poorly controlled animals. In order to ascertain that the abnormalities in the glycosaminoglycan chemistry were related to hyperinsulinaemia rather than hyperglycaemia, six hypophysectomized dogs were treated with $1.5 \mathrm{U} /$ day of porcine protamine zinc insulin, for 3 weeks. Average plasma glucose levels were in the order of $4.3 \mathrm{mmol} / 1$ and plasma insulin levels fluctuated between 9 and $27 \mathrm{mU} / 1$; the latter represented twice the peak value seen in five untreated hypophysectomized dogs. The resulting chemical changes in the glycosaminoglycan content were in line with those encountered in diabetic animals, including the rise in dermatan sulphate content of the coronary arteries. These results indicate that: (1) hyperinsulinaemia produced by injections of insulin causes alterations of the arterial glycosaminoglycan content; (2) not all segments of the arterial tree are equally responsive to insulin and (3) the coronary arteries have a particularly insulin-sensitive dermatan sulphate metabolism.

Key words: Diabetic and hypophysectomized dogs, insulin, arterial glycosaminoglycans.

There appears to be a concensus of opinion that good management of diabetes requires more than normalization of blood glucose levels if coronary heart disease and late vascular complications in general are to be prevented $[1,2]$. The artificial $B$ cell has focused attention on physiological $24 \mathrm{~h}$ plasma insulin profiles in that better blood sugar control was achieved with less insulin when fluctuations in plasma insulin concentrations were brought closer to the normal range $[3,4]$. The present study further emphasizes the importance of maintaining normal insulin levels in that it provides evidence of chemical alterations that develop in the arterial ground substance if dogs are exposed to intermittent hyperinsulinaemia. The nature of the chemical changes, particularly the rise of the dermatan sulphate content in coronary arteries, is compatible with the notion that elevated plasma insulin levels may accelerate the development of diabetic macroangiopathy [2]. 
Table 1. Plasma glucose concentrations $(\mathrm{mmol} / \mathrm{l})$ in normal and diabetic dogs (mean $\pm \mathrm{SEM}$ )

\begin{tabular}{lccccc}
\hline Specimen & \multicolumn{2}{c}{ Clock time $(\mathrm{h})$} & & & \\
\cline { 2 - 6 } & 0800 & 1200 & 1600 & 2000 & 2400 \\
\hline Normal dogs $(\mathrm{n}=8$ ) & $5.8 \pm 0.2$ & $5.8 \pm 0.2$ & $5.3 \pm 0.1$ & $5.3 \pm 0.3$ & $5.8 \pm 0.3$ \\
Diabetic dogs (poor control, $\mathrm{n}=4$ ) & $19.2 \pm 1.0^{\mathrm{a}}$ & $5.8 \pm 1.0$ & $14.6 \pm 0.9^{\mathrm{a}}$ & $20.9 \pm 1.7^{\mathrm{a}}$ & $18.7 \pm 2.9^{\mathrm{a}}$ \\
Diabetic dogs (good control, $\mathrm{n}=6$ ) & $7.3 \pm 2.3$ & $2.7 \pm 0.5^{\mathrm{a}}$ & $10.8 \pm 2.1^{\mathrm{a}}$ & $14.1 \pm 1.9^{\mathrm{a}}$ & $7.6 \pm 1.2$ \\
\hline
\end{tabular}

a Significantly different from normal $(\mathrm{p}<0.01)$

\section{Materials and Methods}

All experiments were performed on male beagles, aged between 9 and 10 months, weighing approximately $10 \mathrm{~kg}$ and purchased from Marshall and Co, New York. It is our experience that such young animals are free of detectable kidney and cardiovascular degenerative lesions.

\section{Diabetic Dogs}

Animals were rendered diabetic by a single IV injection $(60 \mathrm{mg} /$ $\mathrm{kg}$ ) of alloxan monohydrate (British Drug Houses, Toronto). They were housed in metabolism cages to secure $24 \mathrm{~h}$ urine collections and were fed daily at $1000 \mathrm{~h}$. All animals consumed the same measured amounts of commercial dog food (Purina chow and Romar beef chunks). The amount of glucose excreted was determined by using "Clinitest" tablets; proteinuria and ketonuria were checked by "Multistix" reagent strips (all supplied by the Ames Company, Rexdale, Ontario). Animals with proteinuria in excess of trace amounts were excluded from the experiments. All animals were insulin-dependent. They were kept for 100 days and received daily injections of commercially available highly purified porcine insulin (Connaught Laboratories, Toronto) to minimize formation of antibodies [5]. Approximately two-thirds of the daily dose consisted of regular Toronto crystalline insulin (lot \# 1221-1) and onethird of protamine-zinc insulin (PZI, lot \#201434), administered in two separate syringes at feeding time. Fasting blood samples were drawn at weekly intervals and plasma glucose [6], triglycerides [7] and cholesterol [8] were determined by standard procedures.

Diabetic animals were arbitrarily divided into two groups referred to as "poorly controlled" (four dogs) and "well controlled" (six dogs). In the poorly controlled group the daily dose of insulin averaged 14 units/animal, which was enough to prevent ketonuria and weight loss, but the daily glucose excretion was frequently in excess of $10 \mathrm{~g} /$ day. The fasting plasma values for the four animals (mean $\pm \mathrm{SD}, \mathrm{n}=40$ ) were: $18.5 \pm 2.8 \mathrm{mmol} / 1$ for glucose; $0.5 \pm 0.1 \mathrm{mmol} / 1$ for triglycerides; and $5.2 \pm 0.4 \mathrm{mmol} / 1$ for cholesterol. The triglyceride and cholesterol values were comparable to those found in our eight normal controls $(0.5 \pm 0.1$ and $4.1 \pm 0.3 \mathrm{mmol} / 1)$ which reflects the difficulty of producing hyperlipidaemia in dogs. In the well controlled group, enough insulin was injected to reduce glycosuria to $1-5 \mathrm{~g} /$ day. The average insulin requirement was approximately 30 units, i. e. 20 units of regular plus 10 units of PZI. The mean \pm SD for the three blood constituents, determined at weekly intervals in the six dogs $(n=40)$, was: $8.5 \pm 3.0 \mathrm{mmol} / \mathrm{l}$ for glucose; $0.5 \pm 0.1 \mathrm{mmol} / 1$ for triglycerides; and $5.0 \pm 0.6 \mathrm{mmol} / 1$ for cholesterol.

In addition to these determinations, plasma insulin was measured in the fasting samples as well as in blood samples drawn serially on several occasions at 0800 (fasting), 1200 ( $2 \mathrm{~h}$ post- prandially), $1600,2000 \mathrm{~h}$ and midnight. A mean plasma insulin profile was calculated for each dog. The radioimmunoassay of Hales and Randle [9] was employed using the kit of the Amersham Searle Corporation (Rexdale, Ontario). Samples with insulin concentrations in excess of $100 \mathrm{mU} / 1$ were suitably diluted. Less than $10 \%$ of total radioactivity was found to be bound to immunoglobulins in individual plasma samples, indicating that formation of antibodies in response to the administration of pork insulin was indeed negligible. Eight age-matched, normal, untreated beagles served as controls and statistical differences between groups were assessed by Student's $t$ test; $p$ values of less than 0.01 were considered significant.

\section{Hypophysectomized Dogs}

Hypophysectomies were performed by the transbuccal procedure $[10,11]$. Completeness of the hypophysectomy was checked by histological examination of the removed tissue and by post-mortem examination of the sella turcica. After surgery, the dogs remained in the animal colony for 8 weeks without replacement therapy. It is our experience that this interval is sufficient for the gonads and other pituitary-dependent endocrine glands to become atrophic. Five of the animals were then retained as hypophysectomized controls while the other six received one daily injection of PZI insulin at feeding time $(1000 \mathrm{~h})$ for a 3 week period. Hypophysectomized dogs are exquisitely insulin-sensitive and therefore the maximum dose tolerated without hypoglycaemic episodes was $1.5 \mathrm{U}$. Because of the frailty of these hypophysectomized dogs, no weekly blood samples were drawn, but occasional plasma insulin and glucose profiles were done by drawing serial blood samples at 0800 (fasting), 1200 ( $2 \mathrm{~h}$ post-prandially), $1600,2000 \mathrm{~h}$ and midnight. The statistical treatment was the same as for data from diabetic animals.

\section{Glycosaminoglycans}

At the end of the experimental period, i. e. after either 21 or 100 days respectively, all animals were sacrificed by an overdose of sodium pentobarbital. The aorta, common carotid, external iliac, renal and superior mesenteric arteries were removed and cleaned of adventitia, using a magnifying lamp. Special care was taken to remove both coronary arteries with their major branches. The aorta was divided into three segments: the arch, from the valve to the left subclavian artery; the thoracic segment, from the left subclavian artery to the coeliac artery; and the abdominal segment, from the coeliac to the external iliac artery. Neither on inspection nor on routine histology did arteries of diabetic or hypophysectomized dogs differ from normal dogs. Furthermore, the difference between 'wet' and 'dry' weight of corresponding arteries, i.e. before and after acetone-ether extraction, was the same for all groups of animals. 
Details of procedures with references for the isolation and identification of arterial glycosaminoglycans (GAG) are given elsewhere $[12,13]$. In essence, GAG were solubilized by papain digestion and then precipitated with ethanolic potassium acetate and subsequently with cetylpyridinium chloride. Total GAG was estimated as uronic acid by the orcinol technique. Repeat analyses agreed within $10 \%$ (coefficient of variation 0.5 ), as did the results of recovery studies of GAG materials of known composition. Resolution into individual components was accomplished by electrophoresis on cellulose acetate strips in a $0.2 \mathrm{~mol} / 1 \mathrm{ZnSO}_{4}$ buffer at $\mathrm{pH}$ 5.5. Strips were stained with Alcian blue and quantitated in an integrating scanner. GAG components were identified by comparing their mobilities with standard preparations and also by enzymatic digestion with testicular hyaluronidase and chondroitinase $\mathrm{ABC}$. Four fractions were identified: hyaluronic acid, heparan sulphate, dermatan sulphate, and an unresolved mixture of chondroitin sulphates $\mathrm{A}$ and $\mathrm{C}$. Repeat analyses of heparan, dermatan and chondroitin sulphates from arteries or standard preparations agreed within $3 \%$ (coefficient of variation 0.6 ); those of hyaluronic acid within $7 \%$ (coefficient of variation 0.3 ). The sum of values for individual fractions was at least $90 \%$ of the total uronic acid content as determined in the GAG mixture prior to electrophoretic separation. To correct for the loss, each value was multiplied by a factor:

$\mathrm{f}=\frac{\text { uronic acid content of GAG mixture }(\mathrm{mg} / \mathrm{g} \text { dry tissue) }}{\text { sum of fractional uronic acid content ( } \mathrm{mg} / \mathrm{g} \text { dry tissue) }}$

\section{Results}

\section{Diabetic Dogs}

The results of serial plasma glucose and insulin determinations in blood samples drawn at $4 \mathrm{~h}$ intervals are presented in Table 1 and Figure 1, respectively. Since all animals were fed when insulin was administered at $1000 \mathrm{~h}$, peak insulin concentrations were found at $1200 \mathrm{~h}$ in both well and poorly controlled dogs. There were no signs or symptoms of hypoglycaemia, although plasma glucose levels were quite low at $1200 \mathrm{~h}$ in the well controlled group.

The results of arterial GAG determinations in the two groups of diabetic dogs are given in Figures 2 and 3 respectively. Although the four GAG constituents were determined in all eight arterial segments, only data significantly different $(p<0.01)$ from normal controls are presented. A schematic survey of differences indicating the uneven distribution of chemical alterations is presented in Table 2.

On the whole, arteries of well controlled animals, i. e. those exposed to marked insulin fluctuations, tended to show GAG alterations in more than one fraction, while in the poorly controlled animals, with less pronounced plasma insulin changes, the GAG alterations were limited to one sulphated component only. One change which was always observed in both poorly and well controlled diabetic animals was a comparable rise above normal in the dermatan sul-

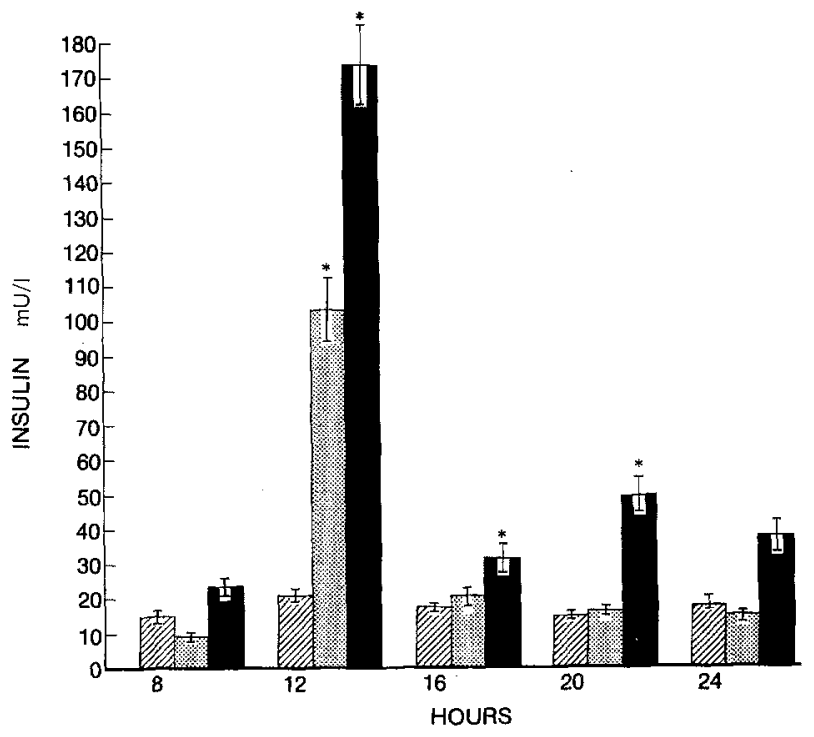

Fig. 1. Plasma insulin values in normal and insulin treated diabetic dogs $($ mean $\pm \mathrm{SEM}) . \mathbb{Z}=\operatorname{normal}(\mathrm{n}=8)$; 圆 = poorly controlled diabetic $(n=4), \quad=$ well controlled diabetic $(n=6)$. *Indicates that differences from notmal controls are statistically significant $(\mathrm{p}<0.01)$

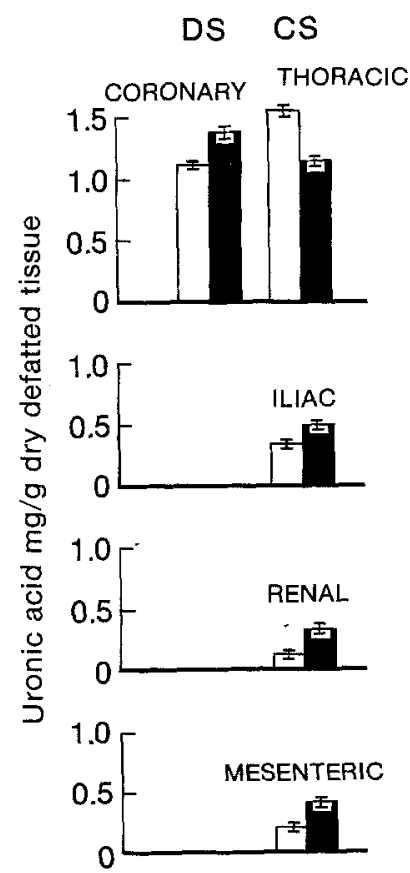

Fig. 2. Arterial glycosaminoglycans in normal and poorly controlled diabetic dogs (mean \pm SEM). $\square=$ normal $(n=8) ; \boldsymbol{\square}=$ poorly controlled diabetic $(n=4)$. All differences are statistically significant $(p<0.01)$. DS $=$ dermatan sulphate; $C S=$ chondroitin sulphate 


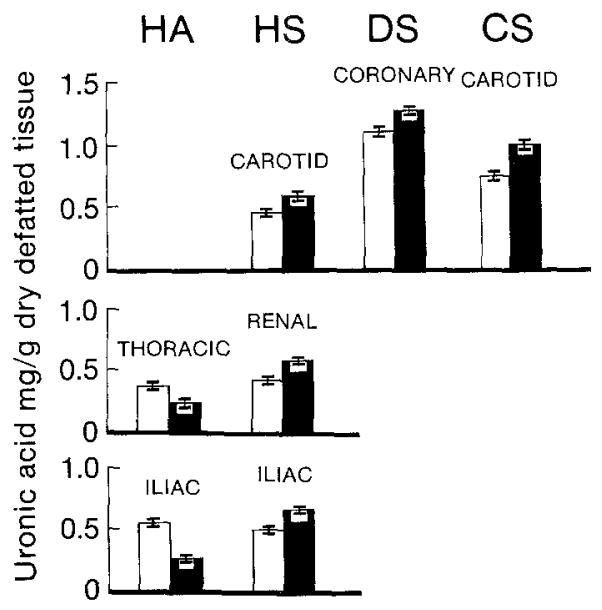

Fig. 3. Arterial glycosaminoglycans in normal and well controlled diabetic dogs (mean \pm SEM). $\square=$ normal $(n=8) ; \square=$ well controlled diabetic $(n=6)$. All differences are statistically significant $(\mathrm{p}<0.01)$. HA $=$ hyaluronic acid; $\mathrm{HS}=$ heparan sulphate; $\mathrm{DS}=$ dermatan sulphate; $\mathrm{CS}=$ chondroitin sulphate

Table 2. Schematic survey of differences in arterial glycosaminoglycans between normal and diabetic dogs

\begin{tabular}{|c|c|c|c|c|}
\hline Artery & $\begin{array}{l}\text { Hyaluronic } \\
\text { acid }\end{array}$ & $\begin{array}{l}\text { Heparan } \\
\text { sulphate }\end{array}$ & $\begin{array}{l}\text { Dermatan } \\
\text { sulphate }\end{array}$ & $\begin{array}{l}\text { Chondroitin } \\
\text { sulphate }\end{array}$ \\
\hline Coronary & & & $a, b$ & \\
\hline $\begin{array}{l}\text { Aorta } \\
\text { Arch }\end{array}$ & & & & \\
\hline $\begin{array}{l}\text { Thoracic } \\
\text { Abdominal }\end{array}$ & a & & & $b$ \\
\hline Carotid & & a & & $\mathrm{a}$ \\
\hline Iliac & a & a & & b \\
\hline Renal & & a & & $\mathrm{b}$ \\
\hline Mesenteric & & & & b \\
\hline
\end{tabular}

Well controlled diabetic dogs, difference from normal controls

b Poorly controlled diabetic dogs, difference from normal controls

phate content of coronary arteries. This consistency is noteworthy both because of the variety of changes that were observed in other vessels, and because of the known affinity of this sulphated GAG for lowdensity lipoproteins [14].

\section{Hypophysectomized Dogs}

In order to study the effects of hyperinsulinaemia in the absence of hyperglycaemia, insulin was administered to exquisitely hormone-sensitive animals with an endocrine derangement completely different from diabetes, namely the hypophysectomized dog.

The serial glucose and insulin levels in insulintreated and non-treated hypophysectomized animals are presented in Table 3 and Figure 4 respectively. Hypophysectomized dogs had lower plasma insulin and glucose levels than did normal dogs. For insulin, the lowering was statistically significant only at a $5 \%$ level, with the exception of midnight when the difference was significant at a $1 \%$ level. Insulin treatment doubled the plasma values within $6 \mathrm{~h}$ after the administration of $1.5 \mathrm{U}$ of PZI (at $1000 \mathrm{~h}$ ), but by the next morning the insulin values were again the same in both groups of hypophysectomized dogs. It is noteworthy that plasma glucose values were not significantly affected by the administration of this amount of insulin.

The results of glycosaminoglycan determinations are given in Figure 5. Although all four GAG fractions were measured in eight arterial segments, only the data significantly different $(p<0.01)$ from hypophysectomized controls are presented. No comparison between normal and hypophysectomized dogs is given, since it is known that hypophysectomy itself significantly lowers the arterial GAG content $[10,11,15,16]$, and this is not a point at issue. The effect of insulin on the GAG distribution in hypophysectomized dogs was not strictly comparable to that seen in diabetic dogs. Nevertheless, a relatively small increase in plasma insulin concentration resulted in statistically significant alterations of the GAG content in five arterial segments, including a rise in dermatan sulphate content of the coronary arteries.

\section{Discussion}

These results provide evidence that conventional administration of insulin exerts a measurable effect on the GAG content of the arterial ground substance. We have reported previously that various segments of the arterial system show differences in response to disturbances in endocrine homeostasis such as diabetes [11, 17], hypophysectomy and replacement therapy with pharmacological doses of a variety of hormones $[10,11,16,17]$. This differential hormone sensitivity was apparent also in the present series of experiments in both diabetic and hypophysectomized dogs treated with insulin. Considering the fundamental difference in the metabolic state of these two types of experimental models, there can be little doubt that the alterations in arterial GAG contents were brought about by insulin per se and were not secondary to hyperglycaemia or other biochemical derangements. This does not preclude the possibility that the latter modified the pattern of insulin response in the various groups of animals. As to hyperglycaemia, the fact that even in poorly controlled diabetic dogs certain arteries showed no change in the steady state concentration while others showed 
Table 3. Plasma glucose concentrations ( $\mathrm{mmol} / \mathrm{l})$ in normal and hypophysectomized dogs (mean $\pm \mathrm{SEM}$ )

\begin{tabular}{|c|c|c|c|c|c|}
\hline \multirow[t]{2}{*}{ Specimen } & \multicolumn{5}{|c|}{ Clock time (h) } \\
\hline & 0800 & 1200 & 1600 & 2000 & 2400 \\
\hline $\begin{array}{l}\text { Normal dogs }(n=8) \\
\text { Hypophysectomized dogs without }\end{array}$ & $5.8 \pm 0.2$ & $5.8 \pm 0.2$ & $5.3 \pm 0.1$ & $5.3 \pm 0.3$ & $5.8 \pm 0.3$ \\
\hline $\begin{array}{l}\text { insulin }(\mathrm{n}=5) \\
\text { Hypophysectomized dogs with insulin }\end{array}$ & $4.2 \pm 0.2^{\mathrm{a}}$ & $4.1 \pm 0.2^{\mathrm{a}}$ & $4.1 \pm 0.1^{\mathrm{a}}$ & $4.0 \pm 0.2^{\mathrm{a}}$ & $4.2 \pm 0.1^{a}$ \\
\hline$(1.5 \mathrm{U} P Z \mathrm{P} / \mathrm{day})(\mathrm{n}=6)$ & $4.4 \pm 0.2^{\mathrm{a}}$ & $3.7 \pm 0.4^{\mathrm{a}}$ & $3.4 \pm 0.2^{\mathrm{a}}$ & $4.6 \pm 0.2$ & $4.7 \pm 0.2^{\mathrm{a}}$ \\
\hline
\end{tabular}

a Significantly different from normal $(\mathrm{p}<0.01)$

either a rise or a reduction of individual constituents, argues against the simplistic notion that increased availability of glucose could lead to GAG accumulation. Since we have no information on the turnover rate of individual components, we are at present unable to comment on the mechanisms responsible for the segmental heterogeneity of GAG alterations.

In previous experiments we have demonstrated a positive correlation between the degree of hormonal responsiveness of the various segments of the canine arterial tree and the propensity to develop degenerative lesions in corresponding human arteries [18]. While hyaluronic acid is chiefly concerned with hydration of tissues [19], sulphated GAG are known to bind low-density lipoproteins, fibrinogen and calcium, and they also interact with platelets $[14,20,21$, 22]. Dermatan sulphate in particular is known to have a strong affinity for binding very low- and lowdensity lipoproteins [14]. In this context, our findings in the coronary arteries are of particular interest. That diabetic dogs controlled on insulin accumulate abnormal amounts of dermatan sulphate in their coronary arteries was reported by us before, but without reference to intermittent hyperinsulinaemia as the possible cause [17]. The consistency with which we continue to observe this rise in dermatan sulphate content of the coronary arteries in both diabetic and non-diabetic hypophysectomized dogs, points to a degree of uniformity and specificity of hormone response that we have failed to observe so far in other arteries. The sensitivity of the coronary dermatan sulphate metabolism is really exquisite if we consider that in the hypophysectomized dog, under similar experimental conditions, neither growth hormone [15] nor the three sex hormones, testosterone, oestrogen and progesterone [16] evoked appreciable effects. The relationship of abnormal circulating insulin levels to atherosclerosis has recently been reviewed by Stout [2], but arterial GAG are not mentioned. We note that Stout found insulin to stimulate proliferation of arterial smooth muscle cells and to promote lipid accumulation.

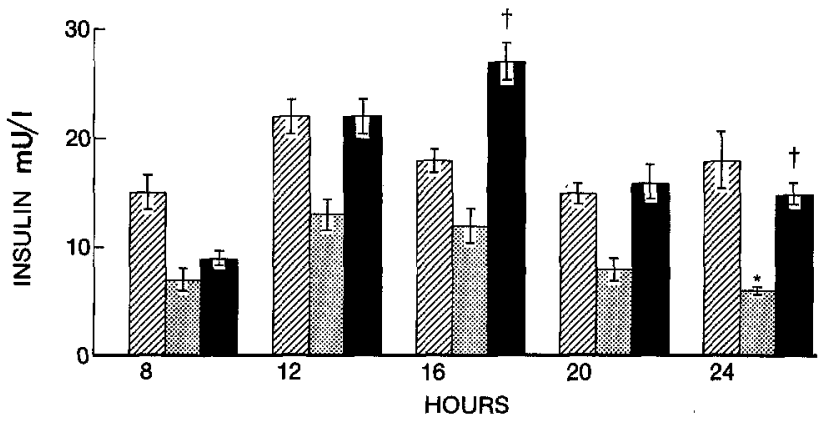

Fig. 4. Plasma insulin values in normal and hypophysectomized dogs (mean $\pm \mathrm{SEM})$. $=$ normal $(\mathrm{n}=8)$; 墖 = hypophysectomized without insulin treatment $(\mathrm{n}=5) ; \mathbf{a}=$ hypophysectomized with insulin treatment $(n=6)$. *indicates that the difference from normal is statistically significant; $\dagger$ indicates the same for difference from hypophysectomized controls $(\mathrm{p}<0.01)$

HA HS DS CS

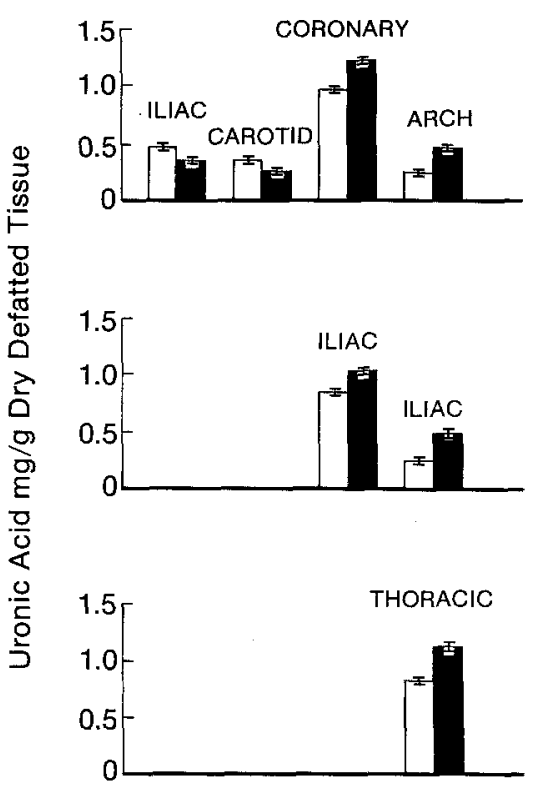

Fig. 5. Arterial glycosaminoglycans in hypophysectomized dogs (mean \pm SEM). $\square=$ without insulin treatment $(\mathrm{n}=5) ; \square=$ with insulin treatment $(n=6)$. All differences are statistically significant $(\mathrm{p}<0.01)$. HA $=$ hyaluronic acid; $\mathrm{HS}=$ heparan sulphate; $\mathrm{DS}=$ dermatan sulphate; $\mathrm{CS}=$ chondroitin sulphate 
Smooth muscle cells are the chief source of arterial GAG, so the sensitivity to insulin is an understandable finding. If we also consider the affinity of the sulphated variety for low-density lipoproteins, we can indeed envisage a sequence of events by which hyperinsulinaemia could contribute to the development of atherosclerosis. In a broader sense, it stands to reason that an artery with an abnormal distribution of GAG in its amorphous ground substance will be more vulnerable than a chemically normal artery to the variety of agents that are known as risk factors in the development of degenerative arterial disease.

Acknowledgements. This work was supported by grants from the Medical Research Council of Canada (MA-6555) and the C. H. Best Fund of the Canadian Diabetes Association. Our thanks are due to Dr. G. Steiner, Department of Medicine, University of Toronto, for the determination of plasma triglycerides and cholesterol, and to Mrs. S. Meredith for expert secretarial assistance.

\section{References}

1. Ducimetiere P, Eschwege E, Papoz L, Richard JL, Claude JR, Rosselin G (1980) Relationship of plasma insulin levels to the incidence of myocardial infarction and coronary heart disease mortality in a middle-aged population. Diabetologia 19: 205-210

2. Stout RW (1979) Diabetes and atherosclerosis. The role of insulin. Diabetologia 16: 141-150

3. Albisser AA, Zinman B, Marliss EB, Botz CK (1980) The metabolic and hormonal responses to glucose infusion in anaesthetized normal and diabetic dogs controlled by an artificial B-cell. Diabetologia 18: 479-485

4. Schade DS, Eaton RP, Friedman NM, Spencer WJ (1980) Normalization of plasma insulin profiles with intraperitoneal insulin infusion in diabetic man. Diabetologia 19: 35-39

5. Neubauer HP, Schöne HH (1978) The immunogenicity of different insulins in several animal species. Diabetes 27: 8-15

6. Hoffman WS (1937) A rapid photoelectric method for the determination of glucose in blood and urine. J Biol Chem 120: 51-55

7. Kessler F, Lederer H (1966) Fluorometric measurement of triglycerides. Technicon Instrument Corporation, Chauncey, New York

8. Levine JB, Zak B (1964) Automated determination of serum total cholesterol. Clin Chim Acta 10: 381-384

9. Hales CN, Randle PJ (1963) Immunoassay of insulin with insulin-antibody precipitate. Biochem J 88: 137-146
10. Brosnan ME, Sirek OV, Sirek A, Przybylska K (1973) Action of growth hormone and thyroxine on aortas of hypophysectomized dogs. Diabetes 22: 243-250

11. Brosnan ME, Sirek OV, Sirek A, Przybylska K (1973) Effect of pancreatectomy, with and without hypophysectomy, and of insulin treatment on the composition of canine aorta. Diabetes 22: $397-402$

12. Breen M, Weinstein HG, Andersen M, Veis A (1970) Microanalysis and characterization of acidic glycosaminoglycans in human tissues. Anal Biochem 35: 146-159

13. Sirek OV, Sirek A, Cukerman E (1978) Effect of hormones on the glycosaminoglycan content of renal arteries. Blood Vessels 15: $259-265$

14. Iverius $\mathrm{PH}$ (1972) The interaction between human plasma lipoproteins and connective tissue glycosaminoglycans. J Biol Chem 247: 2607-2613

15. Sirek OV, Sirek A, Fikar K (1976) Lack of somatotropin effect on glycosaminoglycan content of canine coronary arteries. Endocrinology 99: 1448-1451

16. Sirek OV, Sirek A, Fikar K (1977) The effect of sex hormones on glycosaminoglycan content of canine aorta and coronary arteries. Atherosclerosis 27: 227-233

17. Sirek OV, Sirek A, Cukerman E (1980) Arterial glycosaminoglycans in diabetic dogs. Blood Vessels 17: 271-275

18. Sirek OV, Cukerman E, Sirek A (1978) The relationship of hormones to arterial glycosaminoglycans and atherosclerosis. Med Hypotheses 4: 531-539

19. Ogston AG, Sherman TF (1961) Effect of hyaluronic acid upon diffusion of solutes and flow of solvent. J Physiol (Lond) 156: $67-74$

20. Anderson AJ (1963) The formation of chondromucoproteinfibrinogen and chondromucoprotein- $\beta$-lipoprotein complexes. Chemical and fibrinolytic properties. Biochem J 88: 460-469

21. Urist MR, Speer DB, Ibsen KJ, Strates BS (1968) Calcium binding by chondroitin sulfate. Calcif Tissue Int 2: 253-261

22. Wasteson A, Glimelius B, Busch C, Wastermark B, Hedlin CW, Norling B (1977) Effect of platelets on cell surface associated heparan sulphate of human cultured endothelial and glial cells. Thromb Res 11: 309-322

Received: November 27, 1980, and in revised form: March 17, 1980

Dr. O. V. Sirek

Department of Physiology

Medical Sciences Building

University of Toronto

Toronto, Ontario M5S 1A8, Canada

\section{Note Added in Proof}

Comparable results for dermatan sulphate in coronary arteries were obtained by us with Novo insulins Actrapid and Monotard when injected to diabetic dogs under identical experimental conditions. 